\title{
FACING FACTS ABOUT THE BROADCAST BUSINESS*
}

\author{
DaILAS W. SMYYTHE $\dagger$
}

$\mathrm{T}$ IELEVISION IS A MAJOR INNOVATION which like any other puts stresses on the social organization. It gives rise to problems in many areas: educational policy, family relations, diversion of consumer expenditures from older patterns and so on. It also draws attention to the nature of the institutional organization which was worked out consciously for the commercial use of radio technology. The very process of innovation in the radio industry is dramatically brought to our attention by the dispute over color television standards. Industrial giants like RCA and CBS have contended openly for their respective systems of color television. And in the contest they used extensively the informational services at their disposal. The repercussions from all of these interests in TV could be expected to appear in the serious journals.

One of the issues raised in the color TV controversy is the matter of multiple vs. single standards. While seeming to be, initially, a technical question, this issue is closely related to another: the roles of the market and the government in radio innovation. And in turn this opens up the question of the roles of the market and the government in the conduct of the established broadcast business, both that of television and that of aural radio.

Economists have paid little attention to the unique nature of the broadcast business. It is therefore incumbent on the responsible economist or lawyer when he does discuss broadcast economics to deal carefully with the facts which make it a unique institution. It is particularly confusing to advocate revision of this institution in favor of market controls in a doctrinaire fashion and without regard to these facts. This, spokesmen for broadcast businessmen frequently do by way of special pleading. ${ }^{1}$

A Comment entitled " 'Public Interest' and the Market in Color Television Regulation" in the Summer, 1951, issue of the University of Chicago

* A critique of a Comment appearing in 18 Univ. Chi. L. Rev. 802 (1951). A reply by the student author follows at $\mathrm{p} .106$ infra.

$\dagger$ Research Professor, Institute of Communications Research, University of Illinois.

${ }^{1}$ See, for example, testimony by industry leaders in Hearings before a Subcommittee of the Committee on Interstate and Foreign Commerce on a proposed Amendment of the Communications Act of 1934, Sen. 1333, 80th Cong. 1st Sess. (1947). 
Law Review ${ }^{2}$ directs attention to an important broad issue, namely, the process of innovation in radio. It brings into discussion the roles of the market and government in relation to both radio innovation and the conduct of broadcast business. However, it also offers a graphic illustration of the hazards of applying in sweeping fashion a general body of economic theory to an industry whose facts do not conform to the premises of the theory. The public importance of the issues is too great for the matter to be dropped at this point, and a thoughtful review of the facts and the logic of the Comment seems useful.

The author traces the administrative and litigation history of the most recent dispute over color TV standards. He then isolates as "the most interesting question" the issue "whether the FCC should have permitted both the CBS and RCA systems to operate at once, with the public acting as final judge." He attacks what he calls the FCC's "limited and unwieldy conception of 'public interest' " and proposes that a desirable goal in radio allocation would be a concept of public interest (1) "which did not involve an administrative agency in making this decision," and (2) "which was consistent with current views about the best organization of economic life."

The author then proceeds to sketch the history of radio legislation. This brief survey leads him to conclude that "the most important function of radio regulation is the allocation of a scarce factor of production. . . This is essentially an economic decision, not a policing decision." 3 He then launches his argument for multiple standards in radio with the FCC serving as auctioneer, leasing the frequencies to the bidder offering the highest dollar rental "without making any other judgment of the economic or engineering standards to be used by the applicant." He would have the FCC "still determine the width of channels, but on the basis of one criterionthe maximization of revenue from the leasing of this scarce natural resource."4

At this point, the author develops his argument that the market (as a substitute for the discretion of an administrative agency) might bring about an optimum rate of innovation in broadcasting. Relying on "the logic of the price mechanism in an economy based on free consumer choice" developed by Knight and Lerner, he envisages consumers freely choosing between broadcasting technologies and thus encouraging broad-

218 Univ. Chi. L. Rev. 802 (1951).

3 Ibid., at 809 . The reference to the radio frequency as a "factor of production" views it as the electronic place of business of the broadcaster qua businessman.

1 Ibid., at 811. 
casters to outbid each other for channels. Thus, if equipment manufacturers and broadcast stations pursue maximum profits and the FCC does the same through the leasing of channels, and if competition is substantially perfect, ${ }^{5}$ the problem of choosing standards for innovation is solved. True, not all sets may be able to receive all signals, and this may injure part of the public as well as retard production of TV equipment. He concedes that if the market decisions oscillate between single and multiple standards, "it is not easy to determine which will be greater: the losses to the public because sets will not receive all program transmissions or the gains to that part of the public which, if permitted to choose freely, would choose a more rapid rate of innovation." And he frankly admits several other possible disadvantages ("the rate of obsolescence of receiving sets may be greater than individual consumers would choose for themselves," and "the quality of programs may be adversely affected by a fall in total demand for receiving sets"). Nevertheless, and apparently mainly because the market control notion "is consistent with current views about the best organization of economic life," the present allocation policy is condemned. That policy, he says, "cannot convincingly resolve issues like those involved in the color television controversy." He accordingly sees "a powerful inducement for considering the alternatives."

It is no part of my purpose in this article to comment on the theories of Knight or Lerner as they might apply them outside of the communications field. The application of these theories in the Comment is an intellectual game. And a fascinating game it can be. But, when the author leaves it with a suggested application of his conclusions to reality, he takes it out of the realm in which it is merely the fashion of economists to amuse themselves. The following comments open to examination these assumptions and preconceptions as they relate to the real conditions in the communications sector of the economy.

My initial comment is that the author does not establish a realistic technological frame of reference for his proposal. Indeed his technical views are quite inexplicit. At times he seems to refer solely to broadcasting, but his attack is broadly levied against the FCC's concept of the public interest in all radio allocation. He seems to operate on either or both of two preconceptions in this area: (1) that the broadcast use is the most important, if not the only use of the radio spectrum, and (2) that the frequencies used by broadcasters may be regarded as isolated, technologically, both from each other and from those used for other purposes. Both of these notions are invalid.

${ }^{5}$ The italicized condition is my contribution; the author of the comment does not explicitly recognize it. 
Far from being a dominant user of spectrum space, commercial broadcasting is a minor claimant on it. Reference to an allocation chart would reveal that only 23,050 kilocycles are exclusively devoted to commercial broadcast, while in 72,000 kilocycles commercial broadcast shares the use of the frequencies with one or two nonbroadcast users. ${ }^{6}$ The proportion of the total useful spectrum represented by these magnitudes depends on how the total is defined. Certainly the radio spectrum up to at least $1,000,000 \mathrm{kc}$ is susceptible of commercial exploitation, technologically. On this basis, the exclusive use of frequencies by broadcasters represents 2.3 per cent of the total and the shared use, 7.2 per cent. However, even these small figures may overstate the importance of broadcasting in spectrum allocation terms. The FCC has allocated the spectrum to different users as far as $30,000,000 \mathrm{kc}$. And on this basis commercial broadcasters use exclusively less than one tenth of one per cent, and, on a shared basis, two tenths of one per cent.

ITho are the dominant users of the radio spectrum? The FCC decisions in the General Allocations hearings of $1914-45$, to which reference is made in the first paragraph of the Comment, disclose the heavy use made of radio by the military, the use made of it by law enforcement agencies, fire fighting agencies, the Weather Bureau, the Forestry Service, and the radio amateurs ("hams"), the last of which by definition could hardly be expected to pay for frequency use. ${ }^{7}$ In addition to these noncommercial users of the spectrum there are a number of classes of commercial users other than broadcasters. There are the common carriers by radio-telegraph and radio-telephone. There are the transportation agencies such as vessels on the high seas, ${ }^{8}$ railroads, street railways, buses, trucks, harbor craft, and taxicabs. There are the industries which find specialized use of radio important to their operations, such as electric power, gas and water companies, the petroleum industry (which uses radio both for communication and as an essential part of geophysical exploration), the motion picture industry (which uses radio communication especially on location

\footnotetext{
- Broadçast uses here are taken to include AM, FMI, and TV services, but to exclude international broadcasting which is not commercially supported.

7 See Pike and Fischer, Radio Reports, for the complete rules on allocation. For discussion of policy issues in allocation matters, see Edelman, The Licensing of Radio Services in the United States, 1927 to 1947 (1950); President's Communications Policy Board, Telecommunications, A Program for Progress (1951).

${ }^{8}$ It is curious that in his historical survey of radio legislation, the author of the Comment misses two of the most pertinent features of that history as far as his argument is concerned. One of these is that the original radio legislation, 36 Stat. 629 (1910), as amended, 37 Stat. 199 (1912), 46 U.S.C.A. $\$ 484$ (1928) (Wireless Ship Act of 1910) dealt with the use of radio for the protection of lives and property at sea, and not with radio broadcasting which was to remain undeveloped for about another decade. The other major omission is discussed in note 14 infra.
} 
work), and others. ${ }^{9}$ Surely it is not seriously intended that the noncommercial radio users (such as police), the nonbroadcast common carriers (such as radio-telegraph) ${ }^{10}$ and the nonbroadcast commercial users (such as the oil industry) should compete with dollar bids against the broadcast users for channel allocations.

It is possible that the argument of the Comment might be amended to allow for FCC determination of the allocations for nonbroadcast uses, restricting the proposed market controls for the broadcast uses of the frequencies. This would leave the allocation policy in status quo as far as concerns the relative amounts of spectrum space assigned to each service. It would, however, raise an issue of discrimination. Why should broadcasters be required to pay for the use of channels and common carriers be given them free? This issue might be settled by charging license fees for all commercial users of radio. Such a proposal has been advanced several times in Congressional consideration of budget policy for the FCC since the end of World War II. And it may be argued that such license fees are equitable and desirable." However, under the conditions here assumed such license fees could be quite separate from market control.

Are the frequencies used by broadcasters to be regarded as isolated, technologically, from each other and from those used for other purposes, as the author seems to assume? He implies as much by stating that he would limit the FCC's concern in broadcast allocation to determining channel widths in the interest of maximizing rental income. That broadcast frequency assignments are not so isolated is suggested by the fact stated above: that commercial broadcasters share with nonbroadcast users three times as much spectrum space as they use exclusively. Such sharing is dependent on mutual accommodation of the equipment, power and location of stations. Generally speaking, the power and equipment used on any given channel at any given location may cause intolerable interference on other channels unless the whole is carefully engineered to avoid this result. ${ }^{12}$ And the nature of radio permits such interference between fre-

- The idea of radio as a factor of production appears to have more of its conventional meaning in these industrial uses, none of which is a broadcast service.

${ }^{10}$ Congressional, military and State Department policy considerations often enter into the allocation of channels and the assignment of licenses for radio-telephone and radio-telegraph channels between the United States and foreign countries. And there have been expressions of concern that sufficient channels be assigned for domestic use to insure the development of adequate communications facilities. See Communications Act of 1934, at § 1, 48 Stat. 1064 (1934), 47 U.S.C.A. $\$ 151$ (Supp., 1950).

${ }^{11}$ Australia levies a license fee, based on a percentage of income, on its commercial broadcast stations.

12 See any standard work on radio, e.g., Terman, Radio Engineering (2d ed., 1937); Morecroft, Elements of Radio Communication (2d ed., 1934). 
quencies harmonically related as well as those contiguous to each other in the spectrum. Over the past twenty-five years these technological facts have become imbedded in a substantial body of radio law. ${ }^{13}$

To be more precise, let us consider the limits within which for a given service like television, market controls with multiple standards might be conceivable under the proposal set forth by the author of the Comment. He disposes of the problem with the assertion (p. 810) that

The fact that licensees may use different systems of transmission will make no difference with respect to the natural shortage of channels, so long as interference between frequency channels is avoided. The width of each channel can be determined by the FCC as before, and licensees using the different methods of transmission will have to accept the channel width as a given and unvariable condition within which standards must be worked out.

His concession to central authority is limited to determination of channel width. As far as the casual reader is concerned this might imply that the determination of the geographical location of the stations would be entrusted to the market. Thus the same channel-it might be assumedcould have on it more than one TV station operating on the same or different standards and located as close together as market conditions would justify. Similarly the casual reader might infer that stations on adjacent channels might be located as close together geographically as market conditions made desirable. And likewise one might infer that the power he used for his transmitter was a variable wholly within the station operator's control. Now perhaps the author did not intend that such inferences be drawn; but he said nothing to preclude them and they are not inconsistent with what he did say.

As a matter of fact, any kind of broadcast service depends on the precise determination of these variables: geographic location of stations on the same and adjacent channels, and power. And this is true regardless of whether one is discussing single or multiple standards. It is an engineering fact of life, learned the hard way in the chaotic period of market control of AM broadcasting, July, 1926 to February, 1927, which led to the conscious national decision to abandon the market controls and to substitute statutory and administrative controls as the basis of our radio policy. ${ }^{14}$ In these

13 For example, see Warner, Radio and Television Law (1948).

11 The significance of this phase of radio history seems to have escaped the author. The administration of Secretary of Commerce Herbert Hoover abandoned its efforts to control engineering standards under the Radio Acts of 1910 and 1912 following an adverse opinion by the Attorney General, 35 Ops. Att'y Gen. 126 (1926). One authority says: "During the period from July, 1926 to Feb. 23, 1927, when Congress enacted a new law to regulate radio communication, nearly 200 new broadcasting stations came into existence bringing the total up to 733. The new stations selected whatever frequencies they chose and operated upon them 
respects, then, the suggested market control will be severely circumscribed. Nor is the determination of band (channel) width so neutral or economical a decision as the reader might infer. Broadcast signals may be modulated onto carrier waves in at least three alternative ways: by amplitude, frequency, or pulse-time. And the channel widths required differ for each. According to the plan contained in the Comment, the FCC in setting channel widths would be either precluding innovation of kinds of standards which would require wider channels, or assigning wastefully wide channels if the licensees chose to adopt standards requiring narrower band widths. In the former case, the FCC would be severely limiting the kinds of standards (perhaps in effect prescribing one kind), while in the latter case, it would be chargeable with wasting precious spectrum space.

Within the rigid technological limits which I have mentioned, there would be some room, as a technical matter, in which it would be possible to permit multiple standards within a portion of the spectrum administratively designated for a certain broadcast service. But it is a narrowly circumscribed market freedom in terms of technique. It is a quite strained construct for the indulgence of a certain economic philosophy ${ }_{.}{ }^{15}$

Leaving the area of electronic technique, we may review the nontechnical facts which bear on the proposal of the Comment.

Indispensable to the logic of market controls is the economic assumption that there is substantially perfect competition in the electronics field. This is far from the case.$^{16}$ At the outset it should be noted that the fact of monopoly is technically inherent in the nature of radio. Frequency assignments are limited in number particularly for all stations located in a given area. Land sites in comparison are much less coercive bars to competition

with any desired power regardless of the interference they happened to create for existing American or Canadian stations. Existing stations that were dissatisfied with their assignments jumped to other frequencies and increased power and hours of operation at will. The result was a chaos in broadcasting which has been properly termed the "breakdown of the law." Herring and Gross, Telecommunications; Economics and Regulation 244 (1936). See also, Smythe, A National Policy on Television?, 14 Pub. Op. Q. 461 (1950).

${ }^{15}$ This technical discussion, it is submitted, demonstrates that there is no real analogy between the TV color standards issue and the marketing of three different kinds of phonograph record players (see the Comment, at $815 \mathrm{n}$. 67). One situation involved the radio spectrum; the other does not. Further, that this development of multiple standards in phonograph records is, or will ultimately be, in the public interest has not been and probably cannot be substantiated.

${ }^{18}$ The hearings before the Senate Committee on Interstate Commerce on the bill which became the Communications Act of 1934 are shot through with concern with monopoly in the communications field. Hearings on Sen. 2,910, 73d Cong. 2d Sess. (1934). And see the report on Investigation of the Telephone Industry in the United States, H.R. Doc. No. 340, 76th Cong. 1st Sess. (1939); Danielian, AT \& T; The Story of Industrial Conquest, especially cc. 5-7 (1939). 
than are radio channel assignments. For each frequency assignment confers to some degree a monopoly position on the licensee.

$R C A$ 's position is incomparably stronger than that of CBS. Its patent position is second only in strength to that of American Telephone and Telegraph Company and in television, RCA is dominant. ${ }^{17}$ Its expenditures on research far outstrip CBS and all companies other than AT \& $\mathrm{T}$. In addition to its powerful operating company in the broadcasting field, the National Broadcasting Company, RCA has a large and well-knit organization of plants for the manufacture and marketing of electronics products in general, and radio transmitting and receiving equipment in particular. Over and above the strength of its position vis-à-vis the market itself, RCA has other advantages to a greater degree than its rivals in the radio equipment field. Its position in relation to the formation of public opinion is extremely strong. Through its nationwide marketing organization and through its contacts with other manufacturers in connection with the licensing of its patents, RCA is in a position to obtain extensive support for its policies in matters technological, such as the color standards controversy. Careful review of the trade journals would support the conclusion that the RCA public relations campaign on color standards compensated to some degree for the relative weakness of its technological position in the FCC hearings.

These facts are standing testimonials to the lack of perfect competition in the TV industry. If the rules of market control were imposed on the real world, CBS color would be effectively stopped, and the emergence of any system of color $\mathrm{TV}$ would be delayed. ${ }^{18}$

${ }^{17}$ Television "is covered by an exceedingly formidable patent structure. Patentwise the key company is the Radio Corporation of America; and no concern, so far as $I$ know, manufactures television sets today without paying a royalty to RCA." MacLaurin, Patents and Technical Progress-A Study of Television, $58 \mathrm{~J}$. Pol. Econ. 142 (1950). Of a total of 1,567 suits relating to patents between 1900 and 1941, MacLaurin found RCA plaintiff in 375 with the next most active plaintiff being General Electric with 198. CBS's patent litigation was not significant enough to be mentioned. MacLaurin, Invention and Innovation in the Radio Industry 274 (1949).

${ }^{18}$ See the opinion of Commissioner Robert Jones, dissenting in part, to the First Report of the Commission, Docket Nos. 8736, 8975, 9175, and 8976 (Sept. 1, 1950). He was opposed even to "temporizing" represented by the delay to permit the industry to propose to build bracket standards into new black-and-white sets. In part he said, "In view of the consistent record of the industry thwarting color for ten years, the Commission gambles with the only proponent who has advanced a successful system of color television these ten long years. ... Had the Government thrown its weight against the public's desire to buy and play with the crystal sets, against receivers with morning glory loud speakers and howling signals, on the theory that radio should not be commercialized until superheterodyne and FM were invented, the tycoons of television would be dwarfs today and the radio industry would be but a feeble voice in America. Today we have a color system that has long since passed the howling speaker and crystal set stage. All of the Commissioners have agreed that the field sequential system is as good as black and white was in 1941 when commercial standards were set (for 
A second broad postulate which seems to underlie proposals such as that advanced in the Comment is politico-economic in nature: that the public weal will be served if broadcasting, like grocery stores, uses the conventional business organization, subject only to general legal restraints on its profit-seeking activity. This postulate carries with it, usually, the parallel assumption that the educational and cultural responsibilities of broadcast station operators ought to be no more substantial at the most than those of the operators of the newspapers and magazines. The author of the Comment does accept the former of these assumptions ${ }^{19}$ but he neither avows nor disavows the latter assumption.

The acceptance or rejection of these twin assumptions by an individual is ultimately a matter of taste. But the political economist and lawyer would seem to have an obligation before embracing these dicta to examine the origin and performance of the institution which would be affected by his recommendations. And despite the extensive use made of these two assumptions by business organizations for propaganda purposes, there is a powerful tradition in the United States that the economic, educational and cultural rights and responsibilities of broadcasting are unique. ${ }^{20}$ The history of this institutional process has by no means been definitively studied as yet. My own view was summarized in part recently in the following passage:

After sinewy struggle, the Congress produced the Radio Act of 1927 . It is sufficient for our purpose here to sketch its outline. Fundamental to the new policy was the

TV). Every proceeding must come to an end sometime. The Commission has tested the opinions of the whole industry in the crucible of exhaustive public hearings. It has determined those positions that have been unsound, lacking in imagination, and based upon fear of competition of color with black and white television. The impurities of engineering and economic thought have been burned out by the findings and conclusions to which I adhere. The industry should examine carefully the refined ore so that it may align itself with the public interest. The Commission, on the other hand, should by final decision now cut the Gordian knot which has bound color television for ten years."

19 'An interpretation of the standard of 'public interest' . . . which was consistent with current views about the best organization of economic life, would have very much to recommend it indeed." 18 Univ. Chi. L. Rev. 802, 808 (1951). "This plan has the advantage that the broadcasters are operating in their own economic interests for profit and that its operation is not dependent upon the accuracy with which they follow abstract rules." Ibid., at $811 \mathrm{n} .56$. That there is any "best organization of economic life" is an assumption that exists only in the minds of the author and those who may share his views. Business in this country has worked out its own modus operandi, which only in rare instances approaches the "ideal" contemplated by the author. An indication of how strongly American business would oppose being forced to operate in accordance with the author's standards is available from even the briefest consideration of antitrust proceedings.

${ }^{20}$ With the exception of avowedly partisan expressions on the part of broadcasters themselves, the literature on broadcasting displays agreement on this proposition. See Siepmann, Radio, Television and Society (1950); and FCC, Public Service Responsibility of Broadcast Licensees (1946). 
premise that the radio channels were public property, inalienable. On this premise, the policy built a system of licensing the use of radio channels for short periods of time, not exceeding three years, when their use for broadcast purposes would be in "the public interest, convenience and necessity." The second phase of the policy was to continue private enterprise in the actual operation of broadcast stations. In doing this the Congress took what it had before it: an institution organized partly as a set-manufacturers' sales aid, partly as an advertising medium, and partly as a cultural medium. The third large phase of the policy was an accent on the anti-monopoly sanctions. Congress was impressed with the dangers of monopoly control over broadcasting by means of patents or any of the other devices which the fertile human mind may concoct. It wrote special sanctions into its broadcast policy. Ordinary private enterprise was subject to the Anti-trust laws. Additional penalties were prescribed for broadcasters who violated those laws.

Here, if you please, was born a novel institution-it was certainly not government operation. It was equally certainly not private enterprise as our commerce and industry knew-or know today - the meaning of that term. With still equal certainty it was not the class of business affected with a public interest which we have come to term "public utilities" (for no power to regulate radio prices was asserted, nor ever has been). Faced with a similar problem, Great Britain also set up a unique institution: a public corporation substantially free of political interference and completely lacking in commercialism.

As the curtain falls on our drama, therefore, the audience is left with a provocative problem. A policy was created embodying two sets of values which at times might or might not coincide; namely, the public interest of the listeners and the body politic, and the private interest of the broadcaster businessmen. The subsequent history of broadcasting in the United States can fruitfully be regarded in terms of the pressures playing on this mixed institution. It can usefully be analyzed in terms of the interplay of the often diverse needs and goals comprehended in this-as yet-uneasy paradox. ${ }^{2 I}$

There are many important issues in television (and radio). The restrictions on the market flowing from monopolistic practices in all their guises are one. Lawyers and economists might be both interested and particularly competent to examine the performance of the broadcast businessmen's institution. The same may be said of the challenging problem of how an optimum rate of innovation may be protected, given the continuance of the present institutional patterns for broadcast operation, patents, and antitrust policy. For economists and lawyers concerned with other facets of communications, the meaning of the constitutional provisions bearing on freedom of the press might well be re-examined in the light of the increasing concentration of controls-both within and between communications "media." These are examples of the many kinds of studies which need to be done. And they all have the advantage of being directly reality-oriented. Whatever models are employed in their analysis are likely to be devised to fit the facts. My concern with the law review

"Smythe, A National Policy on Television?, 14 Pub. Op. Q. 461 (1950). 
Comment stems from the fact that it provides an example of the employment of models, constructed for one purpose, in a context where they do not fit, either in assumptions or in facts. Models in principle are useful. In practice, their usefulness is in direct proportion to their appropriateness to the facts and the mores to be analyzed.

\section{REJOINDER}

Professor Smythe's overall objection to the Comment is that facts in the communication industry do not fit the economic theory applied.

He points out first that broadcasting is not the most important use of the radio spectrum. "Surely it is not seriously intended that noncommercial radio users (such as police), the nonbroadcast common carriers (such as radio-telegraph) and the nonbroadcast commercial users (such as the oil industry) should compete with dollar bids against the broadcast users for channel allocations." It certainly is seriously suggested. Such users compete for all other kinds of equipment or else they don't get it. I should think the more interesting question is, Why is it seriously suggested that they shouldn't compete for radio frequencies? If the illusory comfort of free service to government is considered essential, then it would still be possible to treat differently the broadcasting and other segments of the radio spectrum. The result would be that government would be saved from the self-knowledge of what such services cost and, unlike other consumers, would not have to decide whether they were really worth it in comparison with available substitutes.

The next objection is that broadcast frequencies are not isolated technologically from other uses of the radio spectrum. Professor Smythe appears to conclude from the objection that there are peculiar conditions in broadcasting which make it impossible for the rational self-interest of individual participants in the broadcast frequency market to avoid chaos and confusion as it does in other markets. As a result, he is able to conjure up disconcerting possibilities such as interference between different users of the radio spectrum. But the government in maximizing its revenue from frequency channels would inevitably, as any rational entrepreneur, lease them under such conditions as are necessary to avoid conflict between its licensees. In maximizing revenue, it is essential that a landlord avoid chaos or else his tenants move and revenue is not maximized. The landlord of an office building does not permit free access by all tenants to each other's quarters, although within certain limits he permits complete freedom within those quarters. 